\title{
O ENSINO DE CIÊNCIAS NATURAIS E CIDADANIA SOB A ÓTICA DE PROFESSORES INSERIDOS NO PROGRAMA DE ACELERAÇÃO DE APRENDIZAGEM DA EJA - EDUCAÇÃO DE JOVENS E ADULTOS
}

\section{The teaching of Natural Sciences and citizenship under the optics of teachers inserted in the fast learning program EYA - Education of Youths and Adults}

\author{
Patrícia Oliveira Santos ${ }^{1}$ \\ Josiane dos Santos Bispo ${ }^{2}$ \\ Maria Luiza Rodrigues de A. Omena ${ }^{3}$
}

Resumo: O presente estudo teve como objetivo conhecer as concepções dos professores da EJA - Educação de Jovens e Adultos - no aspecto referente à interface ensino Ciências Naturais e cidadania. Serviu ainda para identificar as principais dificuldades encontradas na prática desses docentes para a formação de alunos-cidadãos, assim como revelar a atual situação do ensino de Ciências Naturais no referido programa. Para tanto, foram entrevistados 19 professores que lecionam a disciplina Ciências Naturais nas turmas de $5^{\mathrm{a}}$ a $8^{\mathrm{a}}$ série, inseridas no Programa de Aceleração de Aprendizagem da EJA, em escolas públicas municipais de Aracaju, SE. Como instrumentos de coleta de dados, utilizou-se a técnica de entrevista semi-estruturada e a análise de documentos, com enfoque qualitativo.

Palavras-chave: educação. cidadania. EJA (Educação de Jovens e Adultos). Ciências Naturais.

Abstract: The objective of this study was to know the conceptions of teachers from EYA-Education of Youths and Adults on the teaching of Natural Sciences and Citizenship. It was also used to identify the main difficulties found by the teachers concerning citizenship formation in students, as well as to reveal today's situation for the teaching of Natural Sciences on such program. Therefore, 19 Natural Science teachers from the 5th and 6th grades inserted in EYA's Fast Learning Program were interviewed in public schools of Aracaju, SE. As a data collecting tool, the technique of the semi-structured interview was used, as well as document analysis focusing on quality.

Keywords: education. citizenship. EYA (Education of Youths and Adults). Nature Sciences.

\section{Introdução}

Em sua trajetória, o ensino de Ciências Naturais no Brasil tem se orientado por diferentes tendências que refletem o momento histórico, político e econômico de cada época.

Nas décadas de 1950 e 1960, a substituição da velha base da estrutura agráriocomercial por uma nova estrutura societária urbano-industrial decorrente do desenvolvimento científico-tecnológico, abre espaço para um ensino de Ciências pautado na valorização da participação do aluno no processo de aprendizagem do método científico, por meio de atividades práticas de laboratório, objetivando a formação de futuros cientistas.

\footnotetext{
${ }^{1}$ Licencianda em Ciências Biológicas da Universidade Federal de Sergipe (UFS). E-mail: oliveira@ufs.br

${ }^{2}$ Licencianda em Ciências Biológicas da Universidade Federal de Sergipe (UFS).

${ }^{3}$ Professora do Departamento de Educação da Universidade Federal de Sergipe (UFS).
} 
O novo cenário social provocou significativas mudanças no currículo de Ciências e na educação de base no Brasil, a partir do momento em que passou a considerar a formação do trabalhador peça importante para atender à exigência crescente do desenvolvimento científico-tecnológico, criando um distanciamento entre o que era ensinado em Ciências e o conhecimento necessário à produção científica e ao desenvolvimento da tecnologia.

A partir dos anos 70, em meio ao movimento CTS (Ciência, Tecnologia e Sociedade), marcado por um conjunto de reflexôes sobre o impacto da ciência e da tecnologia na sociedade moderna, o ensino de Ciências incorpora a necessidade de preparar o indivíduo para discutir e refletir acerca das implicaçóes sociais do desenvolvimento científico e da neutralidade da ciência. Concomitantemente, começava-se a pensar na democratização do ensino destinado ao homem comum, que tinha que conviver com o produto da ciência, da tecnologia, e do qual se requeria conhecimento, não apenas como especialista, mas também como futuro político, profissional liberal, cidadão, enfim.

Nos anos 80, tendência reproduzida na década seguinte, a atenção volta-se ao processo de construção do conhecimento científico pelo aluno, a partir do surgimento de diferentes correntes construtivistas, dando lugar a uma circulação de pequenos projetos, centrados na escola e no professor.

Diante da necessidade de atender aos movimentos educacionais progressistas da época, e garantir a todos o acesso ao conhecimento exigido pelo novo modelo societário, o direito à educação de base, estendido aos jovens e adultos, é assegurado pela Constituição Federal Brasileira de 1988.

Essa conquista se apresentou para aqueles que, por algum motivo, não tiveram acesso ao saber sistemático na idade própria como a esperança de conquistar dias melhores, por meio da superação das dificuldades advindas da falta de conhecimento necessário para o exercício da cidadania em uma sociedade de letrados. Neste sentido, merece destaque o trabalho que já havia sido iniciado por Paulo Freire, a despeito da pedagogia da libertação.

$\mathrm{Na}$ atualidade, seguindo a tendência da educação de uma forma geral, as atenções do ensino de Ciências Naturais têm como base a idéia de cidadania e a formação de professores com novos perfis profissionais. Ainda assim, apesar da preocupação com o desenvolvimento pleno do indivíduo, percebe-se que o tema cidadania não foi incorporado por grande parte dos docentes que atuam nas mais diversas disciplinas.

Dada a relevância da contribuição do ensino de Ciências Naturais para a formação do cidadão, o presente estudo buscou conhecer as concepçôes dos professores da EJA na interface ensino Ciências Naturais e Cidadania.

\section{Um paralelo entre a evolução histórica do ensino de Ciências Naturais, a luta pela cidadania e a Educação de Jovens e Adultos no Brasil}

Conforme Kralsichik (2000), o ensino, de forma geral, reflete o momento político, econômico e cultural da sociedade. A cada novo governo, ocorre um surto reformista que atinge principalmente os Ensinos Básico e Médio. Tal fato é nitidamente percebido quando se faz uma análise histórica do ensino de Ciências Naturais em nível global. 
Mundialmente, o desenvolvimento do ensino de Ciências sempre esteve vinculado aos aspectos político-econômicos da época. Países com longa tradição científica, como Inglaterra, França, Alemanha e Itália, definiram cada um, com suas prioridades e inclinações, o que e como se deve ensinar Ciências, do nível elementar ao superior (DELIZOICOV e ANGOTTI, 1992).

No Brasil, a priori o ensino de Ciências foi introduzido no currículo do Ensino Básico como condição da formação do cidadão e para atender às necessidades do desenvolvimento tecnológico do País (MELO, 2000).

Entre os anos 50 e 60, o ensino de Ciências refletiu a situação do mundo ocidental após a Segunda Guerra Mundial. A industrialização, o desenvolvimento tecnológico e científico que vinham ocorrendo não puderam deixar de provocar choques no currículo. É a fase da realização dos grandes projetos, em que há uma preocupação com a elaboração de bons materiais e a adequação das escolas com toda a estrutura possível, inclusive com laboratórios. As escolas foram transformadas em verdadeiros clones de laboratórios, a atividade de ensinar e a manipular o laboratório não era do professor, mas de um expert devidamente preparado para esse fim (KRALSICHIK, 2000; MELO, 2000).

No mesmo período, as manifestações em defesa da educação de base constituíam-se num campo fértil para a proposta de alfabetização de adultos, que ficou conhecida como "método Paulo Freire". É nessa época que a educação de adultos passa a ser percebida como instrumento de libertação e percussora de um processo de democratização do ensino popular e de busca pela cidadania, sendo compreendida como a oportunidade de reflexão sobre o mundo, a posição e o lugar do homem nele (MANFREDI, 1981; SOARES, 2001; VÓVIO, 2001).

Com a imposição da ditadura militar em 1964, o papel da escola modificou-se, deixando de enfatizar a cidadania para buscar a formação do trabalhador, considerado agora peça importante para o desenvolvimento econômico do País. Deste modo, as disciplinas ligadas à formação do trabalhador passaram a fazer parte do currículo, o que determinou a fragmentação das matérias científicas sem que houvesse um correspondente benefício na formação do profissional (KRALSICHIK, 2000).

Por volta da década de 1970, em razão das necessidades geradas pelo desenvolvimento tecnológico do País, o ensino de Ciências, além de visar à formação de cientistas, passa a incorporar mais um objetivo - permitir a vivência do método científico como necessário à formação do cidadão, buscando elaborar um currículo de Ciências que possa integrar ciência, tecnologia e sociedade (movimento CTS). Começava-se, assim, a se pensar na democratização do ensino destinado ao homem comum que tinha que conviver com o produto da ciência, da tecnologia, e do qual se requeria conhecimento, não apenas como especialista, mas também como futuro político, profissional liberal, cidadão, enfim. Sendo capaz de discutir e refletir acerca das implicações sociais do desenvolvimento científico e a neutralidade da ciência (KRASILCHIK, 1987; DELIZOICOV e ANGOTTI, 1992).

Foi no contexto da formação do cidadão, do homem comum e do trabalhador, que a Constituição Federal Brasileira de 1988, atendendo aos movimentos educacionais progressistas da época, instituiu, pela primeira vez no plano legal, o direito ao Ensino Fundamental, inclusive aos que a ele não tiveram acesso na idade própria, incluindo, portanto, os jovens e adultos. 
Santos, P. O. et al.

A ideologia de promoção de cidadãos por meio da educação também foi contemplada na nova LDB - Lei de Diretrizes e Bases da Educação n 9394/96, no artigo 22, que dispõe sobre a Educação Básica, o qual afirma que:

A educação básica tem por finalidades desenvolver o educando, assegurar-lhe a formação comum indispensável para o exercício da cidadania e fornecer-lhe meios para progredir no trabalho e em estudos anteriores.

Sobre a educação fundamental, o Art. 32 assim assegura:

O Ensino Fundamental (...) terá por objetivo a formação básica do cidadão (...).

Dessa forma, a educação passou a ser legalmente reconhecida como instrumento social básico, capaz de possibilitar ao indivíduo a transposição da marginalidade para a materialidade da cidadania, não sendo possível pensar sua conquista sem a aquisição do saber (MARTINS, 2001; TEIXEIRA e VALE, 2001).

Também no ano de 1996, os Parâmetros Curriculares Nacionais (PCN) para o ensino de Ciências Naturais de $5^{\underline{a}}$ a $8^{\underline{a}}$ série do Ensino Fundamental elegeu como um dos objetivos da disciplina a compreensão da cidadania como prática coletiva dos direitos e deveres políticos, civis e sociais, conforme destaca:

O estudante não é só cidadão do futuro, mas já é cidadão hoje, e, nesse sentido, conhecer ciências é ampliar a sua possibilidade presente de participação social e desenvolvimento mental, para assim viabilizar sua capacidade plena de exercício da cidadania.

Para Manzini-Covre (1995), só existe cidadania se houver a prática da reivindicação, da apropriação de espaços, para fazer valer os direitos do cidadão. O que corrobora com a idéia de cidadão citada por Millan (1996), que afirma se tratar do agir social de acordo com as regras próprias da vida compartilhada de forma responsável pela consciência coletiva.

Entretanto, ainda que o sistema brasileiro de ensino tenha aberto espaço para debates no que se refere à educação para a cidadania, pouco se tem discutido sobre como tratar o tema em disciplinas específicas como Ciências Naturais (TEIXEIRA e VALE, 2001).

Essa constatação, aliada às exigências da sociedade contemporânea em relação ao desenvolvimento da ciência, seus resultados e suas aplicações tecnológicas, remete à necessidade de um ensino de Ciências Naturais voltado para o exercício do senso crítico, visando ao desenvolvimento de uma percepção aguçada a respeito dos impactos sociais, culturais e ambientais, decorrentes dos avanços científicos e tecnológicos.

Tal abordagem é meta recomendada pela LDB para o ensino da área de ciências na escola fundamental. É também nesse sentido que os PCN da disciplina sugerem a articulação entre os quatro blocos temáticos propostos: Ambiente, Ser Humano e Saúde, Recursos Tecnológicos e Terra e Universo. Como sugere o documento, o tratamento dos conteúdos deve favorecer a construção de uma visão de mundo, que se apresenta como um todo formado por elementos inter-relacionados, entre os quais, o homem, agente de transformação. 
Em se tratando da EJA, é importante levar em conta que o aluno se encontra inserido no mundo do trabalho e das relações interpessoais, trazendo consigo uma história mais longa (e provavelmente mais complexa) de experiências, conhecimentos acumulados e reflexôes sobre o mundo externo, sobre si mesmo e sobre as outras pessoas, necessitando a escola valorizá-la, se possível dentro do conteúdo das disciplinas, de forma transversal, como também sugerem os PCN.

\section{A formação do professor de Ciências no Brasil - problemas e perspectivas}

Os cursos de licenciatura têm sido objeto de críticas em relação à sua possibilidade de preparar docentes, tendo em vista a fragmentação das disciplinas da área de educação no que tange à área de formação específica do professor (KRASILCHIK, 1987). Na maioria das vezes, os conteúdos desses dois campos do saber são vistos sem uma intercomunicação, e priorizam a exposição de concepções teóricas "prontas e verdadeiras", para os quais cabem discussão e questionamento (PÉREZ, 1996).

De acordo com Krasilchik (1987), a situação agrava-se ainda mais em razão da expansão do Ensino Superior por meio das "licenciaturas curtas" que se disseminaram por todo o País, em decorrência da necessidade de formar professores de maneira rápida e generalista.

Para Pérez (1996), o processo de formação do professor não se encerra com a aquisição do diploma de nível superior, este se constitui em apenas um estágio dos diversos e infinitos que o professor deverá passar enquanto atuar como educador. A formação do professor deve ser continuada, sendo necessário, a atualização em relação às novas concepções de ensino, a fim de adquirir condiçōes de escolher adequadamente qual concepção teórica atende aos objetivos educacionais. Daí a importância de uma formação sólida e reflexiva, como também estar sempre pronto a buscar novos conhecimentos. É nesse contexto que a formação incipiente dos docentes se apresenta como um dos maiores obstáculos para a aplicação de inovações no ensino, impedindo-os de refletir, experimentar e agir para a concretização do processo de ensino-aprendizagem.

Ademais, aspectos como o rápido processo de proletarização dos professores, a desvalorização profissional e a situação degradante da condição de ensino, seguramente afetam as atividades de docência.

Percebe-se, pois, a necessidade de qualificar-se adequadamente os professores de Ciências, que, além do conhecimento profundo dos conteúdos da disciplina a serem trabalhados, também devem estar cientes do seu papel como cidadãos e formadores de cidadãos. Além disso, as políticas públicas devem possibilitar aos docentes as condições mínimas necessárias para um melhor desempenho de suas funções.

De acordo com Santos (2006), os cursos de formação de professores de Ciências deveriam empenhar-se em preparar profissionais capazes de saber programar atividades de aprendizagem que despertem uma visão interdisciplinar da ciência, uma certa familiaridade com o contexto entre valores e atividades científicas.

\section{Estrutura e organização da EJA no município de Aracaju-SE}

A Educação Básica de Jovens e Adultos teve sua implantação em 1987, por meio do Projeto de Alfabetização de Adultos, em convênio com a Fundação Educar. Nessa época, 
o município de Aracaju passou a prestar atendimento a nove escolas no período noturno, apresentando uma proposta político-pedagógica de atendimento às especificidades do aluno/trabalhador, seus interesses e perspectivas (BRASIL, 1998).

Pautada nessa nova política da EJA (Educação de Jovens e Adultos), a Secretaria Municipal de Educação de Aracaju - Semed - assumiu a responsabilidade do projeto de Educação Básica para a clientela jovem e adulta, tendo como amparo legal o Parecer 331/91 do Conselho Estadual de Educação, norteado pela indicação de Brasil (1998), em relação ao direito do aluno "à escolarização básica com características próprias e conteúdos que refletem e explicam sua realidade, valorizando sua experiência sociocultural".

Atualmente, o município de Aracaju oferece na modalidade de Educação de Jovens e Adultos (EJA) dois programas destinados ao Ensino Fundamental:

- PAEJA (Programa de Aceleração da Educação de Jovens e Adultos), I segmento da EJA, que abrange as Escolas da Rede Pública Municipal de Aracaju, oferecendo o Ensino Fundamental em nível de $1^{\mathrm{a}}$ a $4^{\mathrm{a}}$ série;

- Projeto de Aceleração do Ensino Fundamental no segmento de $5^{\mathrm{a}}$ a $8^{\mathrm{a}}$ série, II segmento da EJA, destinado aos alunos com idade mínima de 14 anos completos ou a completar até o início das atividades letivas.

Dentre os objetivos do Projeto destaca-se a implantação gradativa das classes de Aceleração do Ensino Fundamental - II segmento - $5^{\mathrm{a}}$ a $8^{\mathrm{a}}$ série na Rede Pública Municipal; a correção da defasagem em idade/série e a execução de um currículo compatível com a legislação vigente.

\section{Consideraçôes sobre o método}

O método de pesquisa utilizado foi a abordagem qualitativa. A análise de dados tem base nas respostas obtidas dos docentes por meio da técnica de entrevista semi-estruturada, procurando articular com a pesquisa bibliográfica realizada. Toda a trajetória de análise, por meio de sucessivos confrontos, procurou refletir sobre as concepções dos sujeitos entrevistados no aspecto referente à interface ensino Ciências Naturais e cidadania.

Dos depoimentos, foram extraídos fragmentos que revelavam a visão dos professores da EJA acerca do tema tratado. Os dados coletados durante as entrevistas foram gravados em fita cassete, após se obter a aquiescência dos entrevistados, e posteriormente transcritos em editor de texto. As entrevistas tiveram duração média de 30 minutos, porém algumas atingiram 50 minutos de gravação.

\section{Os interlocutores envolvidos}

Participaram do estudo 19 professores (um professor por escola) que lecionavam a disciplina Ciências Naturais, no período noturno, nas 19 escolas públicas municipais. Cada escola pesquisada apresentava apenas um professor responsável pela disciplina Ciências Naturais no curso noturno da EJA. Em relação à formação dos docentes na ocasião da pesquisa, 31,5\% (6) estavam em fase de conclusão do curso de licenciatura em Biologia, e portanto, encontravam-se na função de estagiários. Dos professores diplomados, $15,7 \%$ (3) eram licenciados em pedagogia, e os demais, 52,8\% (10) eram licenciados em Biologia.

Estes docentes possuíam entre dois e trinta anos de formados e trabalhavam com a EJA num intervalo de dois a vinte anos. 


\section{Análise dos dados}

No sentido de melhor retratar as concepções dos professores, foram selecionados os seguintes aspectos de análise, observados na fala dos sujeitos sociais entrevistados: concepçóes de cidadania, educação e cidadania, Ciências Naturais e cidadania, envolvimento da escola, motivação dos alunos, tempo disponível para planejamento das aulas, qualificação do docente, disponibilidade de materiais e equipamentos.

\section{Concepções de cidadania}

Demo (1996) define cidadania como sendo a qualidade social de uma sociedade organizada sob a forma de direitos e deveres majoritariamente reconhecidos, em que no lado dos deveres, destacaria-se o compromisso comunitário de cooperação e co-responsabilidade.

Sendo assim, compreende-se que o exercício da cidadania não se restringe apenas ao cumprimento de direitos e deveres já estabelecidos, mas a participação nas conquistas de novos direitos que devem ser refletidos pelo grupo de acordo com as exigências do mesmo.

A solicitação para que os professores respondessem acerca do que entendem por cidadania tinha a pretensão de identificar o reflexo dessas concepções na sua prática docente. No entanto, verificou-se, na maioria das respostas, uma concepção de cidadania restrita, em grande parte relacionada a direitos e deveres, como se pode observar no depoimento a seguir.

... seriam cidadãos conscientes de seus deveres e direitos.

A expressão "conscientes de seus deveres e direitos" remete tão somente à transmissão de informaçôes ao indivíduo, as quais lhe possibilitem o exercício da cidadania. No entanto, é válido lembrar que uma concepção de cidadania restrita apenas à ciência de direitos e deveres, sem mencionar a sua prática efetiva, não é suficiente para a atuação plena do cidadão. É preciso torná-los válidos e buscar novos direitos que expressem as necessidades de todos.

Nesse contexto, Martinez (1997) acredita que uma nova ordem constitucional não significa direitos garantidos, no entanto, por outro lado, sem o respaldo jurídico e político, não há a mínima possibilidade desses direitos se estenderem aos segmentos sociais como um todo, por isso, exercer a cidadania significa conquistá-la e lutar pelo cumprimento dos direitos já adquiridos.

Portanto, é possível inferir que a prática sustentada a partir, apenas, da ciência de direitos e deveres, dificilmente passará de uma ação educativa conformista e acrítica.

Dois outros docentes assim definiram cidadania:

Defino cidadania como sinônimo de criticidade.

A gente tem que formar o cidadão para que eles tenham um futuro melhor. Para que eles sejam bem-aceitos a onde chegar. A gente tem que formar essas pessoas para quando elas chegarem lá fora não terem dificuldades de encontrar um emprego bom e ser alguém na vida.

A despeito do primeiro depoimento, pode-se concordar que de fato, para o exercício da cidadania, é imprescindível que o indivíduo revele sua capacidade crítica. Contudo, se essa criticidade não estiver acompanhada de atitudes que possibilitem a transformação social, visando ao bem-estar coletivo, a idéia de cidadania fica apenas no campo teórico. 
É possível que o posicionamento desse professor possa conferir à sua prática o desenvolvimento do pensamento crítico do aluno, no entanto, pode-se incorrer no erro de não despertar no educando a capacidade de agir, de transformar, ou seja, de exercer a cidadania em sua plenitude.

No grupo de entrevistados, apenas dois docentes demonstraram uma visão mais ampla acerca do conceito de cidadania.

Nós estamos vivendo sem cidadania, então, falar da não cidadania fica bem mais fácil. Você não tem trabalho, não tem alimentação, não tem teto, você só não tem. Por isso prefiro ser pragmático em dizer que cidadania em nosso país é para uma classe bem privilegiada, dentre as quais estão os nossos políticos.

O ser cidadão é o ser participativo, a cidadania exige uma participação efetiva do indivíduo nos mais variados contextos sociais, seja em nível de política, esportes, aspectos culturais e outros. Tem que ser um indivíduo que venha questionar, reivindicar, sugerir, um sujeito transformador, não acomodado a situações que the apresenta, sujeito a imposiçôes.

O primeiro depoimento deixa clara uma compreensão de cidadania como busca da eqüidade social e da promoção da igualdade entre os desiguais, o que só é possível por meio do acesso aos serviços básicos essenciais como educação, moradia, saúde e emprego entre outros. Porém, é relevante lembrar que a reivindicação e a busca pela validação dos direitos adquiridos também se constituem em práticas cidadãs.

Para se restaurar a cidadania, é importante mobilizar e estimular comportamentos solidários. E, nesse sentido, a atuação docente pode revelar-se como difusora de ideologias que visem a colaborar para o resgate da cidadania ameaçada.

Já no segundo depoimento, encontram-se destacados pontos-chave que definem a cidadania, a exemplo dos termos: participação, reivindicação e transformação.

\section{Educação e Cidadania}

Conforme Martins (2001), a materialização do exercício da cidadania requer o conhecimento formal que deve promover a capacitação e a segurança no agir social, e neste contexto, a educação se oferece como instrumento social básico que possibilita ao indivíduo a transposição da marginalidade para a materialidade da cidadania.

Entretanto, observa-se que embora o papel da educação na formação de cidadãos numa perspectiva de transformação social seja claramente reconhecido e exaustivamente discutido entre profissionais e estudiosos da área, contraditoriamente, o discurso não é posto em prática.

Ao questionar os docentes sobre a relação existente entre educação e cidadania, todos foram unânimes em afirmar que é impossível se chegar à concretização da cidadania sem educação. Os discursos demonstram o conhecimento por parte desses agentes da necessidade da educação no processo de participação e modificação social.

\section{Ciências Naturais e cidadania}

Em relação ao ensino de Ciências Naturais como instrumento colaborador da formação de cidadãos, os professores entrevistados demonstraram reconhecer que a abordagem 
da disciplina pode favorecer modificações na postura dos alunos. Conforme deixaram transparecer, valendo-se do entendimento dos estudantes em relação ao mundo e fazendo com que compreendam a dinâmica da natureza, assim como o seu papel enquanto ser integrante da mesma, o ensino de Ciências pode contribuir para uma mudança de atitudes por parte dos discentes que venha a refletir em sua qualidade de vida.

As abordagens acerca da relação do ensino de Ciências Naturais e cidadania seguiram a linha de construção dos dois discursos que seguem:

Se você não conhecer o meio ambiente (a importância da água, do ar, do solo), como você vai ter consciência que precisa preservar isso? Se você não conhecer seu corpo..., a si próprio..., como você vai ser cidadão?

Para ser cidadão tem que questionar em nível de meio ambiente, de exploração de recursos naturais. Sem dúvida, discutir sobre o aproveitamento da água, a importância do petróleo... e todo esse conhecimento, está relacionado a melhores condições de vida.

Sob essa perspectiva, Melo (2000) afirma que:

educar é essencialmente político e o professor também o é. Não se pode ficar restrito ao universo de sua disciplina. É preciso que ele, como agente social ativo, possa discutir com os alunos a importância deles na construção da sociedade e de optarem "política e ideologicamente" qual o melhor caminho a trilharem nas ciências e no seu ensino, que possa atender às necessidades sociais contribuindo para a formação de um aluno cidadão.

Levando em consideração as particularidades da clientela da EJA, é importante salientar que a maioria já está inserida no mundo do trabalho, demonstrando urgência na compreensão de aspectos do desenvolvimento científico e tecnológico e, desse modo, o ensino de Ciências representa a chance de esses jovens e adultos conquistarem melhores condições de trabalho.

De acordo com Santos (2006), tal direcionamento deve estar embasado em propostas mais adequadas para o ensino de Ciências, de modo a favorecer uma aprendizagem comprometida com as dimensões sociais, políticas e econômicas que permeiam as relações entre ciência, tecnologia e sociedade. Trata-se, assim, de orientar o ensino de Ciências para um reflexo mais crítico acerca dos processos de produção do conhecimento científico-tecnológico e de suas implicações na sociedade e na qualidade de vida de cada cidadão.

Por outro lado, o mesmo autor indica três dificuldades encontradas pelos professores de Ciências para promover o ensino de Ciências com esse objetivo. A primeira refere-se à forma tradicional como a escola e alguns elementos que compõem os currículos estão organizados, a exemplo da fragmentação das áreas das ciências (Física, Química, Biologia, Matemática...). A segunda decorre do receio que muitos professores têm, em particular os de Ciências, de discutir temas relacionados com valores. Fugindo dessas questôes, as aulas se mantêm em patamares seguros e a ciência é considerada como neutra. 
A terceira questão, e que parece dificultar sobremaneira um ensino de Ciências voltado para a cidadania, é o habitual distanciamento entre os conceitos científicos aprendidos em sala de aula e as questões científicas verdadeiramente relevantes para a vida das pessoas.

Os aspectos indicados por Santos (2006) ratificam o critério de análise a seguir, referente à relação entre o envolvimento dos agentes escolares e a formação do cidadão.

\section{Envolvimento da escola}

A falta de envolvimento da escola é citada pela maioria dos entrevistados, que reclamam por uma integração maior entre professores e a instituição em que trabalham, como uma das dificuldades para promover a integração ensino de Ciências Naturais e cidadania. Os mesmos consideram importante, também, a disponibilização de recursos que tornem o ambiente escolar mais atrativo para os alunos.

O ideal é que o curso noturno fosse um curso atraente, com mais opções para motivar nossa clientela porque alguns já estão fora da escola há um certo tempo. Para que este retorno seja continuado, a escola deveria ser mais aparelhada para oferecer aos alunos aulas mais lúdicas, mais vibrantes e não tornar o ensino noturno enfadonho.

De acordo com Santos (2006), a escola atualmente se encontra fortemente comprometida com um ensino de qualidade e com a idéia de construção da cidadania, só que ainda sob perspectiva teórica, pois, na prática, as dificuldades encontradas pela escola para a realização de tais ideais são grandes. A precariedade vivida pelos professores, a falta de condições de trabalho, a falta de ação dos responsáveis por mudar essa situação, entre tantos outros fatores, produz um relativo descrédito na transformação real da escola.

Outro aspecto importante mencionado pelos professores entrevistados está relacionado ao elevado índice de evasão, pois de acordo com dados sobre a matrícula na Rede Municipal de Ensino de Aracaju poucos alunos chegam a concluir o curso fundamental (BRASIL, 1998). A constatação remete ao pronunciamento dos professores a respeito da necessidade do curso noturno ser atraente, de forma que os alunos se sintam motivados a levarem-no adiante.

\section{Motivação dos alunos}

A desmotivação dos alunos foi outro aspecto freqüentemente mencionado pelos professores como sendo mais um obstáculo para a formação de alunos-cidadãos:

A grande maioria não tem perspectivas, a gente escuta deles: "pra que estudar, se quando a gente vai procurar um emprego, só vai ganhar um salário?". Realmente, existe um freio muito grande, uma resistência muito forte, porque a perspectiva de futuro para conseguir dias melhores é pequena. Eu sempre digo para eles que é possível vencer, mas mesmo assim é muito difícil.

\section{Tempo disponivel para planejamento das aulas}

A falta de tempo para planejar as aulas igualmente foi destacada pelos professores como sendo um entrave. 
Falta tempo para eu me planejar; estruturalmente, a instituição não oferece muito; qualidade, eu não acredito que eu tenha tanta qualidade para promover um ensino voltado para a cidadania.

Sempre que o professor procura se qualificar, ele geralmente não tem tempo e dinheiro para investir. Esse sistema não qualifica os professores para isso. Eles não querem saber se o professor tem qualificação para dar aulas na EJA.

Falta tempo para eu me planejar. Esta afirmação remete à proletarização do professor por meio da desvalorização profissional e suas condições degradantes de trabalho. O professor ganha mal e é obrigado a trabalhar em vários lugares acabando por desempenhar um trabalho inconsistente e pouco criativo. Como reflexo disso, passa a ser alvo de críticas de análises superficiais que atribuem todas as falhas do sistema educacional ao professor.

\section{Qualificação do docente}

Outro ponto destacado foi a falta de qualificação do docente.

... eu não acredito que eu tenha tanta qualidade para promover um ensino voltado para a cidadania.

O fato de a formação do professor nas universidades brasileiras ocorrer de forma fragmentada em relação às disciplinas específicas e às da área de educação, implica, na prática, uma atuação profissional pouco ousada. Ademais, não existe um programa efetivo para proporcionar formação continuada desses docentes quando saem das universidades.

No campo da EJA, a situação é mais preocupante ainda, uma vez que a maioria dos professores que atuam nesta área nunca tiveram um treinamento ou capacitação para tal, e isso se confirma com a resposta de um dos docentes.

Eles não querem saber se o professor tem qualificação para dar aulas na EJA.

Quando se perguntou aos professores se eles participavam de cursos de formação continuada na área da EJA, todos responderam em consenso que não.

A clientela da EJA possui especificidades que devem ser tratadas de forma cautelosa, pois geralmente esses alunos apresentam baixa auto-estima por trazerem consigo uma história de fracasso pessoal. Além disso, muitos alimentam grandes expectativas em relação à educação, depositando nela todas as chances de recuperar sua identidade pessoal e cultural dentro da sociedade onde vivem.

Atuar nesse sentido requer profissionais habilitados para lidar com essas pessoas, sem frustrar suas esperanças de sucesso, sendo imperativo que o docente se encontre capacitado para desempenhar tal papel.

\section{Disponibilidade de materiais e equipamentos}

A falta de materiais e equipamentos foi outra dificuldade apontada com freqüência para a efetivação da interface entre Ciências e promoção da cidadania. Segundo os professores: 
... para que eles tenham um preparo bom mesmo, a gente teria que ter um laboratório. No laboratório, a gente pode trabalhar com os seres vivos e eles iriam ter uma aprendizagem bem melhor.

Tal afirmação remete aos anos 50 e 60, fase dos grandes projetos, em que o objetivo inicial era formar cientistas. Nessa época, a ciência saiu dos laboratórios hermeticamente fechados e foi inserida no contexto escolar. De acordo com Melo (2000), ainda que, nesse período, a ênfase dada à manipulação do laboratório, para nós, tivesse um entendimento equivocado na forma e no conteúdo de fazer ciências, não se pode negar que significou um marco importante para as ciências e para a educação, pois aos poucos se foi desmistificando a idéia que fazer ciência era um privilégio restrito a alguns "malucos".

No entanto, deve-se deixar claro que se as atividades laboratoriais forem puramente demonstrativas, ou seja, restringirem-se apenas à repetição de metodologias que levarão a um resultado pronto e acabado, não trarão nada de novo para os alunos e, portanto, não haverá uma aprendizagem efetiva.

Arruda e Laburu (2002) mencionam que a ausência de aulas experimentais é freqüentemente apontada pelos professores como uma das principais deficiências no ensino das disciplinas científicas no Ensino Fundamental e Médio, por diversas razões já bem conhecidas, tais como: falta de laboratórios e equipamentos nos colégios; número excessivo de aulas o que impede uma preparação adequada de aulas práticas; desvalorização das aulas práticas; ausência de professores laboratoristas; formação insuficiente do professor, principalmente entre os licenciados em Ciências Naturais e Biologia, pois esses cursos têm tendência de privilegiar conteúdos de Biologia, e acabam resultando em dificuldades por parte dos docentes para abordar assuntos relacionados a outras áreas.

O comentário inferido reforça mais uma vez a importância da formação dos professores, que deve ser sólida, consistente e continuada.

Ao serem questionados se as condições de trabalho que possuem possibilitam educar para a cidadania, apenas dois, dos 19 professores entrevistados, disseram que não. Todos os demais afirmaram que "Sim, é possível, mesmo diante de todas as dificuldades". Ao serem inquiridos sobre a forma como tal intenção poderia se configurar na prática, obteve-se de um dos professores a seguinte declaração:

Trabalhar com projetos é uma opção, fica mais fácil eles transferirem isso para a vida deles. Por exemplo, no turno da manhã, eu trabalhei com projeto de higiene, nós tivemos práticas de como se deve cuidar da higiene pessoal e manter sua casa um ambiente limpo e agradável, longe de doenças. Os alunos confeccionaram cartazes, gibis e até fizeram uma encenação. Muitas alunas que já são mães vieram me dizer, depois, que agora sabiam o jeito correto de ensinar para os seus filhos como escovar os dentes.

O mesmo professor que sugere trabalhar com projetos, admite a dificuldade de se fazer isso no turno da noite, porque, segundo ele, os alunos não demonstram interesse por nada.

Mas a gente sabe também que é mais fácil a gente fazer isso no turno da manhã ou tarde, eles são mais interessados. Trabalhar assim no turno da noite é complicado, porque eles não mostram interesse para nada. 
O que o professor não deve ter percebido ainda é que, ao se decidir trabalhar com um projeto, este tem de ser pensado para um determinado grupo alvo. Talvez o projeto desenvolvido para as turmas do turno da manhã não atenda às necessidades das turmas do período noturno, haja vista que são outras pessoas, com expectativas, pensamentos e realidades diferentes.

A opção de trabalhar com projetos pode realmente proporcionar uma maior aproximação entre o aluno e o professor.

A dinâmica proporcionada pela prática dos projetos pode levar à participação efetiva dos alunos na construção do seu próprio conhecimento, além de possibilitar o diálogo e a vivência de situaçôes que os tornem mais conscientes.

Como se pode observar nos depoimentos que seguem, embora boa parte dos professores tenha afirmado que é possível educar para a cidadania, as respostas dadas são inconsistentes e não demonstram como isso se configuraria na prática.

\footnotetext{
Não só passando sua experiência como pessoa, enquanto ser humano, mas a gente procura mostrar para eles que tem que usar essa bagagem para que futuramente tenham melhores dias de vida.

A tarefa é difícil, mas a gente tenta. As escolas da prefeitura são periféricas, então, a situação de convivência geral é complicada. Mas acho que a gente fazendo com que eles conheçam seus direitos e deveres é possível.
}

Krasilchik e Marandino apud Santos (2006) apontam algumas sugestôes de como o ensino de Ciências pode desenvolver o senso crítico dos alunos, por meio de reflexões acerca de valores e questões cotidianas que devam ser discutidas em sociedade. Uma das sugestôes consiste, num primeiro momento, em se propor leituras de textos provenientes de pesquisas acerca do assunto escolhido, principalmente de jornais e revistas. As informações adquiridas servirão de base para a argumentação e o professor ficará encarregado de prover textos adequados para leitura. Num segundo momento, o professor distribui categorias de personagens importantes no debate, compondo com os alunos o cenário da discussão. Por fim, o debate que deverá enfocar o papel da ciência e sua relação com a qualidade de vida e como deve a sociedade se organizar para não fazer uma análise ingênua e simplista da questão. Espera-se criar um clima de discussão no qual os alunos argumentem de acordo com sua personagem, mesmo que não concordem com o papel que estão representando.

No entanto, os mesmos autores ressaltam ser importante que essas sugestôes variem de acordo com a diversidade social e cultural e com o potencial educacional da unidade escolar.

A ênfase dada remete aos alunos da EJA, cuja maioria é de trabalhadores que, muitas vezes, não entendem a complexidade, a importância e a relação existente entre o desenvolvimento científico-tecnológico e o trabalho que desempenham no campo, na fábrica, no comércio etc., embora manipulem produtos resultantes do progresso científico.

A despeito desse fato, Betto (1994), realizando trabalhos educativos com operários e agricultores, percebeu que estas pessoas têm, com o real, uma relação de manipulação.

Para eles, o saber é fazer. Sabem montar uma máquina porque montam; sabem cultivar a terra porque cultivam; (...) Assim, a educação deve propiciar um 
aprendizado manual-intelectual, lidando com símbolos do real e com suas representações, através de dramatizações e de outros recursos que envolvam, no processo educativo, todo ser do educando: o corpo, a voz, os sentidos, os movimentos (...) É desvelando a realidade a partir do que eles fazem que chegam a perceber o rumo, o sentido histórico de sua prática.

\section{Considerações finais}

De acordo com a análise feita, tornou-se evidente que uma das maiores dificuldades, senão a maior, é o não reconhecimento por parte dos docentes do seu efetivo papel de colaborador para a concretização do exercício da cidadania. Ainda que entendam a importância da sua prática na formação de alunos-cidadãos, ao que parece, os professores não internalizaram claramente a idéia, pois, nenhuma ação tem sido feita com essa finalidade.

Levando em consideração as concepções de cidadania citadas pelos professores é possível inferir que as limitações destas refletem em uma prática pouco ousada e ainda menos criativa.

Contribui ainda para tal deficiência a realidade de trabalho que os professores vivenciam, na qual se apresentam como obstáculos para a promoção da cidadania:

- ausência de integração entre escola, professor e comunidade, no desenvolvimento das ações escolares;

- desconhecimento dos princípios constantes da proposta da EJA no município;

- falta de um planejamento voltado às necessidades e peculiaridades dos alunos;

- ausência de cursos de capacitação docente, principalmente, na área de educação de jovens e adultos;

- desmotivação por parte dos alunos;

- a desvalorização profissional que acarreta a proletarização do professor.

Observa-se que a formação dos professores se apresenta como um ponto crucial para se alcançar uma prática pedagógica capaz de possibilitar a construção do aluno-cidadão. No caso da Educação de Jovens e Adultos, especificamente, entende-se que o professor deve estar preparado para lidar com as especificidades que esta clientela apresenta, uma vez que se tratam de pessoas que vivem a exclusão do conhecimento sistemático e, em sua maioria, expressam sentimento de inferioridade e depositam nesse retorno à vida escolar grande parte da esperança de resgate à sua dignidade e na possibilidade de inserção no mercado de trabalho.

Ainda em relação à formação dos professores, torna-se relevante lembrar dos riscos que se corre confiando turmas da EJA a docentes com pouca experiência, como é o caso dos estagiários, que representam $31,5 \%$ do quadro de professores dessa modalidade de ensino no município de Aracaju. Esses riscos incluem desde o desconhecimento dos objetivos do ensino de Ciências Naturais, no qual está incluso o desenvolvimento da cidadania, até o despreparo por parte dos docentes (estagiários), para adoção de métodos adequados à clientela da educação de jovens e adultos.

Ademais, a probabilidade de insucessos da prática desses professores (estagiários) se torna mais significativa quando os mesmos não têm um suporte metodológico, científico e profissional exigidos, como ocorre na maioria das escolas pesquisadas. 
As considerações inferidas até o momento suscitam a necessidade de mudanças em diversos âmbitos no campo da EJA, que vai desde os recursos físicos até os humanos.

Seria necessário que a Secretaria Municipal de Educação de Aracaju (Semed) tornasse real a possibilidade de formação dos profissionais que atuam na EJA, centrando sua atenção na capacitação continuada.

Proporcionar recursos para dinamizar as aulas seria outra providência a ser tomada pela Semed, lembrando que estamos vivendo em uma época de tecnologia, portanto, é imprescindível tornar possível o acesso aos produtos resultantes dos avanços científicos para que os alunos possam desenvolver habilidades exigidas no mundo contemporâneo.

Em relação à atuação da escola, esta tem de se tornar mais efetiva, de forma a corroborar com a prática dos professores envolvidos. A sugestão de trabalhar com projetos pedagógicos, citada por um dos professores mencionados, é algo que poderia possibilitar uma integração maior entre toda a comunidade escolar. Além do que, a metodologia dos projetos propicia a capacidade de simular situaçóes reais, o que reforça o aprendizado e a conscientização do aluno no processo ensino-aprendizagem.

\section{Referências}

ARRUDA, S. M.; LABURU, C. E. Considerações sobre a função do experimento no ensino de ciências. In: NARDI, R. Educação em ciências da pesquisa à prática docente, 3. São Paulo: Escrituras, 2001. p. 53-60.

BRASIL. Lei n. 9.394, de 20 de dezembro de 1996. Estabelece as Diretrizes e Bases da Educação Nacional. São Paulo: Saraiva, 1996.

. Secretaria Municipal de Educação. Educação para jovens e adultos: Proposta curricular $1^{\circ}$ segmento. Ministério da Educação/MEC, 2001. p. 5-35; 161-203.

Semed/SE, 1998.

Projeto de Aceleração do Ensino Fundamental no segmento de $5^{a}$ a $8^{a}$ série. Sergipe:

DElizOICOV, D.; ANGOTTI, J. A. Metodologia do ensino de Ciências. São Paulo: Cortez, 1992.

DEMO, P. Participação é conquista. São Paulo: Cortez, 1996. p. 176.

FREIRE, P.; BETTO, F. Essa escola chamada vida: depoimentos ao repórter Ricardo Kotscho. São Paulo: Ática, 1994.

GRAÇA, A. O. da. Análise da proposta de educação ambiental desenvolvida na educação de jovens e adultos da Escola Estadual "Jorge Amado", localizada em Nossa Senhora do Socorro Sergipe. Brasília, 2003. 120f. Monografia (Especialização em Formação de Formadores em Educação de Jovens e Adultos). Faculdade de Educação - Universidade Federal de Brasília.

KRASILCHIK, M. O professor e o currículo das ciências. São Paulo: EPU, 1987.

2000.

. Reformas e realidade: o caso do ensino das ciências. Perspectiva, v. 14, n. 1, p. 85-93, 
MANFREDI, S. M. Política e educação popular. 2. ed. São Paulo: Cortez, 1981.

MANZINI-COVRE, M. de L. O que é cidadania. 3. ed. São Paulo: Brasiliense, 1995.

MILAN, Y. M. M. N. O educador como promotor da cidadania. Rev. Educação e Ensino. v. 1, n. 1, p. 71-83, mar/ago. 1996.

MARTINEZ, V. C. O cidadão de silício. Marília: Unesp: Faculdade de Filosofia e Ciências, 1997. p.130.

MARTINS, R. B. Educação para cidadania: o projeto político-pedagógico como articulador. In: VEIGA, I. P. A.; REZENDE, L. M. G. de. Escola: espaço do projeto político-pedagógico. 4. Campinas: Papirus, 2001. cap. 3, p. 49-73.

PÉREZ, D. G. Formação continuada de professores de Ciências: no âmbito ibero-americano. Campinas: Autores associados, 1996.

MELO, M. do R. de. Ensino de Ciências: uma participação ativa e cotidiana, 2000. Disponível em: <http://www.rosamelo.hpg.com.br/>. Acesso em: 8 de abril de 2006.

SANTOS, P. R. dos. O Ensino de Ciências e a idéia de cidadania. Mirandum. Ano X. n. 17.2006.

SOARES, M. B. Paulo Freire e a alfabetização: muito além de um método. In: VÓVIO, L. C. et al. Módulo Integrado I - Fundamentos de Educação de Jovens e Adultos. Sesi: Educação continuada, Formação de Formadores, 2001. Unidade I, p. 38 - 40.

TEIXEIRA, P. M. M.; VALE, J. M. F. do. Ensino de Biologia e Cidadania: problemas que envolvem a prática pedagógica de educadores. In: NARDI, R. Educação em ciências da pesquisa à prática docente. São Paulo: Escrituras, 2001. Cap. 2, p. 23-39.

TOMAZI, N. D. Sociologia da educação. São Paulo: Atual, 1997. p. 34-46.

VÓVIO, L. C. et al. Módulo Integrado I - Fundamentos de Educação de Jovens e Adultos. Sesi: Educação continuada, Formação de Formadores. 2001.

Artigo recebido em junho de 2005 e selecionado para publicação em novembro de 2005. 